\title{
Economic cost of malaria on households during a transmission season in Khartoum State, Sudan
}

M.H. Mustafa ${ }^{1}$ and M.A. Babiker ${ }^{2}$

$$
\begin{aligned}
& \text { التكاليف الاقثمادية التي تتحمَّلها الأسرة بسبـب الملاريا في موسم سراية المرض في ولاية الخرطوم، } \\
& \text { بالسوردان } \\
& \text { منى حسن مصطفى، منيف عبد الباقي بابكر }
\end{aligned}
$$

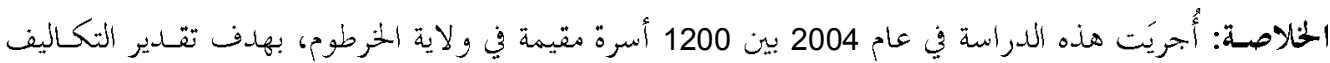

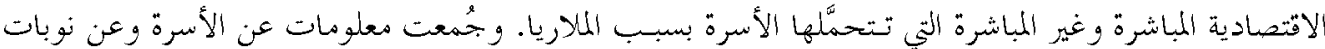

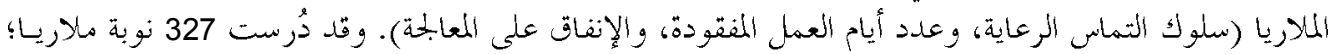

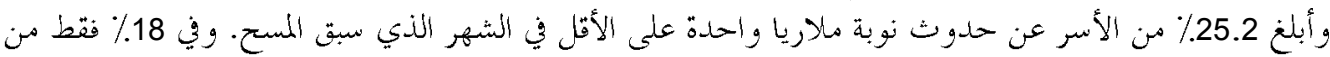

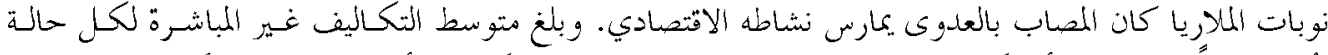

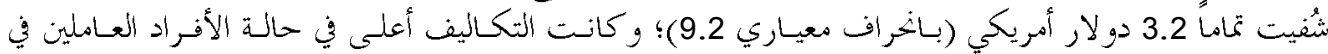

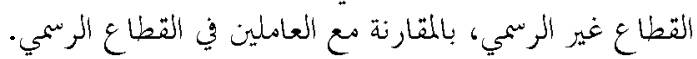

ABSTRACT This study was conducted in 2004 among 1200 households in Khartoum to estimate the direct and indirect economic costs of malaria for households. Information on the household and the malaria episodes was collected (care-seeking behaviour, working days lost and expenditure on malaria treatment). There were 327 episodes of malaria; $25.2 \%$ of the households reported at least 1 malaria episode during the month preceding the survey. In only $18.0 \%$ of malaria episodes was the individual economically active. The average treatment expenditure per fully cured case was US\$ 6.3 (SD 5.9). The average indirect cost per fully cured case was US\$ 3.2 (SD 9.2); it was higher for individuals working in the informal sector than those employed in the formal sector.

Coût économique du paludisme pour les foyers de l'État de Khartoum (Soudan) au cours d'une saison de transmission

RÉSUMÉ Cette étude, menée en 2004 auprès de 1200 foyers de Khartoum, avait pour objectif d'évaluer les coûts économiques directs et indirects du paludisme pour les foyers. À cette fin, il a été procédé à la collecte d'informations sur les foyers et les accès palustres (comportement de recours aux soins, absentéisme et dépenses liées au traitement antipaludéen). II a été recensé 327 accès palustres et $25,2 \%$ des foyers ont rapporté au moins un accès dans le mois précédant l'enquête. Seuls $18,0 \%$ des accès palustres ont frappé un individu économiquement actif. Pour chaque cas de guérison complète, le coût moyen du traitement s'élevait à USD 6,3 (E.T. 5,9), tandis que le coût indirect était de USD 3,2 (E.T. 9,2), ce dernier s'avérant plus élevé pour les travailleurs du secteur informel par comparaison avec le secteur formel.

${ }^{1}$ Research Department, Khartoum State Ministry of Health, Khartoum, Sudan (Correspondence to M.H. Mustafa:mhmhs67@hotmail.co).

${ }^{2}$ Department of Economics, Faculty of Economics and Social Studies, University of Khartoum, Khartoum,

Sudan.

المجلة الصحية لشرق المتو سط، منظمة الصحة العالمية، المجلد الثالث عشر، العدد Y، V.... 


\section{Introduction}

In addition to the health burden, malaria places an enormous economic burden on households in endemic regions [1]. The burden includes the direct cost (medical consultation, laboratory investigation, drugs and hospitalization) [2] and the indirect cost due to work days lost through morbidity and mortality for both malaria cases and individuals looking after them [3,4].

As in many other parts of Sudan, malaria represents a major public health problem in Khartoum State. In Khartoum, malaria accounts for $24 \%$ of all patients seen at outpatient departments and $13.4 \%$ of hospital admissions [5]. In terms of the health burden of malaria on the community, these figures mean that malaria not only consumes the greater share of the treatment-related expenditure of households than other diseseses, but is also the cause of the highest loss of working days.

Although the exact economic burden that falls on households in Khartoum is not known, it is expected to vary from one subgroup of the population to another. There are a large number of possible determinants that may affect the level of economic loss by households [6]. For instance, as regards direct cost, the level of treatment-related expenditure is affected by the care-seeking behaviour of the patient [7]. During malaria episodes patients can chose from a wide range of health care providers or they may resort to self-treatment. As drug and service prices differ from one health care provider to another, the level of expenditure will vary according to the provider chosen.

The indirect cost, on the other hand, depends on the economic activity and type of job of the malaria cases and the family member looking after him/her.

Estimating the total and differential economic cost in Khartoum State is vital to guide health planners and also to bring to their attention the full picture of the devastating effect of malaria.

The objectives of the study therefore were to estimate the direct and indirect costs associated with malaria episodes at the household level in Khartoum State, and to identify the possible effects of care-seeking behaviour and occupation of malaria cases on these costs.

\section{Methods}

\section{Study design and setting}

This was a descriptive cross-sectional community-based study. It was conducted in Khartoum State in 2004, the capital of Sudan; the state is the smallest state of Sudan with an area of $28000 \mathrm{~km}^{2}$. The total population is estimated as 7 million. Khatroum state consists of central urban areas, peripheral rural areas and camps established to accommodate the internally displaced populations (IDPs) coming from other states of the country. It is considered as an area of unstable malaria transmission with high peaks of incidence during, and immediately after, the rainy season, and during the winter months [8].

\section{Sampling}

The primary sampling unit was the household. To be included in the study a household had to have resided for at least 12 months in Khartoum State. For the sample size calculation it was assumed that the proportion treated for malaria during the previous month would be $25 \%$ based on the results of a previous study [9]. Thus a sample of 1200 households was required.

Using the probability proportional to size method, 25 geographically defined clusters were selected from a sampling frame provided by the Central Bureau of

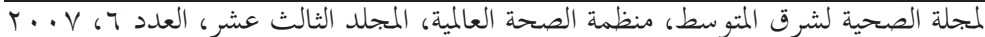


Statistics. The frame was stratified by rural area, urban area and IDP camp. Systematic sampling was used to select 48 households from each cluster to give the total of 1200 households (in total 1203 household were included).

Data were collected in 3 phases to cover the period of the rainy transmission season of 2004. The rainy season usually extends from July to October. The first phase of the study was conducted during the second half of August 2004, the second phase during the first half of October 2004 and the last phase during the second half of November 2004. Thus 400 households were visited in each phase.

The inclusion criteria of malaria cases were:

- Malaria confirmed by positive blood film or other blood tests.

- Malaria diagnosed on a clinical basis by a health care provider.

- For non-confirmed cases the diagnosis was verified by asking about the presence of the following symptoms: fever, headache, sweating and vomiting. These were found to be associated with a positive blood film for malaria using binary logistic regression in a previous study [10].

An individual was considered to have 2 or more malaria episodes if a minimum period of 2 weeks had elapsed between the 2 episodes. In this study all episodes where included.

\section{Questionnaires}

Two questionnaires were used for data collection; both were adapted from the questionnaires used for estimating the malaria-related costs in Sri Lanka [1].

Questionnaire 1 was used with all selected households to collect background information.
Questionnaire 2 was used with all malaria cases to collect the following data: background information on malaria cases, care-seeking behaviour, working days lost and expenditure on malaria treatment.

The reliability and validity of the data were tested by reliability analysis using SPSS and the analysis yielded an alpha value of 0.0009 .

\section{Data collection}

Data were collected by 5 teams each composed of 1 field supervisor and 3 interviewers. The field supervisors were social science graduates who were previously trained on data collection methods and field supervision, and they had received further training on the field-work and the tools of the this study. The interviewers were university graduates, previously trained on data collection methods and had received training on the tools of this study. The training in both instances was conducted by the principal investigator and included lectures and role play.

\section{Data analysis}

Data were analysed with SPSS, version 11.5. The analysis included descriptive statistics for frequencies and averages [mean and standard deviation (SD)], and comparison between subgroups using the chisquared test for proportions, and one-way analysis of variance and $t$-test for means of independent samples. A $P$-value less than 0.05 at $95 \%$ confidence interval was considered significant.

Cost calculations included treatment-related expenditure (direct cost) and indirect costs. Average treatment-related expenditure was estimated first for the household and then per fully cured malaria case. The measurement of indirect costs was based on an output-related approach. The estimates 
included only days lost by malaria cases and their caretakers who were involved in productive work. Productive work was broadly defined as involvement in any economic activity with the potential to add to the disposable income of the household. This output-related method excluded time loss of economically inactive patients [ 1$]$.

The total number of working days lost by both patients and their caretakers was recorded. The indirect cost was calculated for the level of both households and fully cured malaria cases.

\section{Results}

\section{Sociodemographic data}

The 1203 households included 6836 people. The majority $(72 \%)$ of the households participating in the survey resided in urban areas, $20 \%$ in rural areas, while only $8 \%$ resided in IDP camps. The majority of the heads of the households were involved in some income-earning activity (95.2\%). The average monthly income per household was equivalent to US\$216.8 (SD 430.8).

\section{Malaria incidence}

Only $25.2 \%$ of the households reported at least 1 malaria episode during the month preceding the survey. A total of 327 malaria episodes occurred during the 3 phases of data collection and no individual reported having malaria more than once during the study period. The incidence of malaria episodes was $51 / 1000$ in the first phase, $42.5 / 1000$ in the second phase and 51/1000 in the third phase giving an overall incidence of 48.2/1000 per month during the whole period of the survey.

Table 1 shows the characteristics of the individuals who suffered a malaria episode. More than half of the malaria episodes (57.2\%) occurred among females. About two-thirds occurred among the adult popu- lation (> 14 years). In only $18.7 \%$ of the episodes was the individual who contracted malaria covered by health insurance.

In only $18.0 \%$ of malaria episodes was the individual involved in economic activities. Of the economically active individuals, $44.1 \%$ worked in the formal sector and had regular salaries, i.e. government and private sector employees and public sector workers. The remaining $55.9 \%$ belonged to the informal sector (self-employed, farmers and casual labourers) and their earnings were irregular. The average monthly income per malaria case was US\$ 127.9 (SD 72.9) (Table 2).

\section{Care seeking behaviour}

The majority of reported malaria episodes $(78.9 \%)$ were diagnosed by a positive blood film, while $14.4 \%$ were clinically diagnosed at a health facility. Self-diagnosis was observed in only $6.7 \%$ of the episodes.

In $89.3 \%$ of episodes, the individual went to a health facility to seek care in the first instance; only $5.8 \%$ resorted to self-treatment. For the remaining $4.9 \%$,

Table 1 Characteristics of malaria episodes, Khartoum State, 2004

\begin{tabular}{lcr}
\hline Characteristic & No. $(\boldsymbol{n}=\mathbf{3 2 7})$ & $\%$ \\
\hline Sex & & \\
$\quad$ Male & 140 & 42.8 \\
$\quad$ Female & 187 & 57.2 \\
Age group (years) & 110 & 33.6 \\
$\quad 0-14$ & 217 & 66.4 \\
$\quad>14$ & & \\
Heath insurance coverage & 61 & 18.7 \\
$\quad$ Covered & 266 & 81.3 \\
$\quad$ Not covered & & \\
Average income per & \\
malaria case [Mean (SD)] & US\$ 127.9 (72.9) \\
\hline SD = standard deviation. &
\end{tabular}

المجلة الصحية لشرق المتوسط، منظمة الصحة العالمية، المجلد الثالث عشر، العدد Y، V... 
Table 2 Distribution of episodes according to economic activity, Khartoum State, 2004

\begin{tabular}{|c|c|c|}
\hline Economic activity & No. $(n=3$ & $\%$ \\
\hline \multicolumn{3}{|l|}{ Economically active } \\
\hline \multicolumn{3}{|l|}{ Formal sector (regular salary) } \\
\hline Government employee & 14 & 4.3 \\
\hline Private sector employee & 8 & 2.4 \\
\hline Public sector workers. & 4 & 1.2 \\
\hline \multicolumn{3}{|c|}{ Informal sector (irregular earnings) } \\
\hline Farmer & 2 & 0.6 \\
\hline Self-employeda & 20 & 6.1 \\
\hline Casual labourerb & 11 & 3.4 \\
\hline \multicolumn{3}{|l|}{ Economically inactive } \\
\hline Housewife & 79 & 24.2 \\
\hline Unemployed & 36 & 11 \\
\hline Student & 92 & 28.1 \\
\hline Pre-school child & 58 & 17.7 \\
\hline Retired & 3 & 0.9 \\
\hline Total & 327 & $100 \%$ \\
\hline \multicolumn{3}{|c|}{$\begin{array}{l}\text { aSelf employed denotes any individual who owns } \\
\text { his/her business and works for himselflherself instead } \\
\text { of as an employee of another person or organization, } \\
\text { drawing income from a trade or business. He/she } \\
\text { usually owns or shares the capital of the business. } \\
{ }^{b} \text { Casual labourer are unskilled or semi-skilled labourers } \\
\text { who work in areas such as construction and domestic } \\
\text { service - they usually work for very short duration of } \\
\text { time for an employer, and are usually paid for their } \\
\text { labour on a daily basis. Their earnings are irregular and } \\
\text { depend on the availability of a job. }\end{array}$} \\
\hline
\end{tabular}

the individual made blood investigations without consulting a health care provider, consulted a traditional healer or ignored the illness. The governmental health centres were the facilities most commonly used, by $46 \%$ of those seeking care from a facility. Private health facilities (clinics or hospitals) were the least used facilities, used by only $1 \%$ of the cases. After taking all the actions, $97.2 \%$ of the malaria cases were fully cured of the illness (as reported by the individual or his/her family), while in $2.8 \%$ the person was still taking treatment. The 318 fully cured cases were further analysed to estimate the costs.

\section{Lost working days}

The average number of working days lost by malaria cases was 6.2 (SD 6) days. Only $26(8 \%)$ of the malaria cases needed another family member to absent him/herself from work or school to take care of them. Of these co-patients, 19 (73.1\%) were involved in economic activities (employees, selfemployed regular and casual labourers), while $7(26.9 \%)$ were students. The average number of working days lost by co-patients was 3.1 (SD 1.6) days. The study showed that $35.1 \%$ of the economically active malaria cases and $47.6 \%$ of the economically active co-patients had obtained paid sickleave for the period of absence from work. These were mainly employed in the formal sector.

\section{Treatment related expenditure}

The average monthly expenditure on malaria treatment per household was equivalent to US\$ 1.7 (SD 4.1); this reduced the average monthly income per household by $0.8 \%$ (Table 3 ).

At the individual level, the average expenditure per fully cured malaria case was found to be US\$ 6.3 (SD 5.9) and the median was US\$ 6.6. This reduced the average monthly income per malaria case by $5.3 \%$ (Table 3). Table 3 also shows that seeking treatment from a health facility was associated with significantly higher expenditure per fully cured malaria case than resorting to self-treatment [health facility $=$ US\$ 6.4 (SD 5.6), self-treatment $=$ US\$ 2.5 (2.2); $P$ $<0.05]$. Taking more than one action was associated the highest treatment-related expenditure $(P<0.05)$.

As shown in Table 3, private clinics and hospitals were associated with significantly higher treatment expenditure per fully cured malaria case than all the other facilities $[($ private clinic $=$ US $\$ 16.2($ SD10.1), gov- 
Table 3 Average monthly treatment-related expenditure according to actions taken and type of health facility visited, Khartoum State, 2004

\begin{tabular}{|c|c|c|}
\hline Expenditure & Mean (SD), US\$ & $\begin{array}{c}\% \text { reduction } \\
\text { in monthly income }\end{array}$ \\
\hline \multicolumn{3}{|l|}{$\begin{array}{l}\text { Monthly expenditure on treatment per } \\
\text { household }(n=1203) \text {, excluding nutrients }\end{array}$} \\
\hline and food & $1.7(4.1)$ & 0.8 \\
\hline \multicolumn{3}{|l|}{ Expenditure on malaria treatment per fully } \\
\hline cured malaria case $\left(n=315^{a}\right)$ & $6.3(5.9)$ & 5.3 \\
\hline \multicolumn{3}{|l|}{ Actions taken } \\
\hline Self-treatment $(n=13)$ & $2.5(2.2)$ & $P<0.05$ when \\
\hline Blood testing without consultation $(n=7)$ & $5.1(2.2)$ & comparing between \\
\hline Visited health facility $(n=265)$ & $6.4(5.6)$ & different actions \\
\hline More than one action $(n=30)$ & $8.7(8.9)$ & \\
\hline \multicolumn{3}{|l|}{ Health facility chosen } \\
\hline Governmental hospital $(n=61)$ & $5.4(2.1)$ & $P<0.05$ when \\
\hline Governmental health centre $(n=132)$ & $5.0(2.7)$ & comparing between \\
\hline NGO health centre $(n=55)$ & $5.0(1.7)$ & different facilities \\
\hline Private clinic $(n=37)$ & $16.2(10.1)$ & \\
\hline Private hospital $(n=2)$ & $12.2(8.5)$ & \\
\hline
\end{tabular}

ernmental health centre $=$ US\$ $5.0(\mathrm{SD}$ $2.7)$, nongovernmental organization (NGO) centre $=$ US\$ $5.0($ SD 1.7); $P<0.05)]$. When breaking down the treatment-related expenditure, it was found that the highest proportion of treatment expenditure $(42 \%)$ went for purchasing drugs. This was followed by doctor's fees which constituted $30.4 \%$ of the expenditure.

\section{Indirect costs}

Table 4 shows that the average indirect cost of malaria per household per month was US\$ 0.8 (SD 4.9), reducing the average monthly income of households by $0.4 \%$.

The average indirect cost per fully cured malaria case (patient days only) was US\$ 2.6 (SD 8.7) reducing the average monthly income of malaria cases by $2 \%$. The average indirect cost per fully cured malaria case (co-patient days) was US\$ 0.5 (SD 3.4). The overall average indirect cost per fully cured malaria case (both patient and co-patient days) was US\$ 3.2 (SD 9.2).

Individuals who were self-employed and casual labourers had significantly higher average indirect costs per fully cured malaria case than employees and public sector workers: self-employed $=$ US\$ 22.1 $(\mathrm{SD} 17.2)$, casual labourers $=$ US\$ $13.5(\mathrm{SD}$ 10.9), employees US\$ 7.6 (14.7), public sector workers $=$ US\$ $9.0($ SD 14.3); $P<$ 0.0001

\section{Discussion}

Information on the economic consequences of malaria on households is an important complementary tool needed for successful

المجلة الصحية لشرق المتو سط، منظمة الصحة العالمية، المجلد الثالث عشر، العدد Y، V... 


\begin{tabular}{lrc}
\hline \multicolumn{3}{l}{ Table 4 Average monthly indirect cost of malaria, Khartoum State, 2004 } \\
\hline Average monthly indirect cost per: & Mean (SD), US\$ & $\begin{array}{c}\text { \% reduction } \\
\text { in monthly } \\
\text { income }\end{array}$ \\
& $0.8(4.9)$ & 0.4 \\
\hline Household $(n=1203)$ & $2.6(8.7)$ & 2.0 \\
Fully cured malaria case (patient days) & $0.5(3.4)$ & 0.4 \\
Fully cured malaria case (co-patient days) & & \\
Fully cured malaria case (patient and co- & $3.2(9.2)$ & 2.5 \\
patients) & & \\
Type of job & $7.6(14.7)$ & 1.6 \\
Employee ( $n=22)$ & $22.1(17.2)$ & 2.0 \\
Self-employed $(n=20)$ & $9.0(14.3)$ & 5.8 \\
Public sector worker $(n=4)$ & $13.5(10.9)$ & 3.0 \\
Casual labourer $(n=11)$ & $40.6(34.0)$ & 14.3 \\
Farmer $(n=2)$ & & \\
\hline
\end{tabular}

$\mathrm{P}<0.0001$ when comparing between different jobs.

$S D=$ standard deviation

formulation of policies in areas such as health financing, introduction of new therapies, and regulation of the private sector.

\section{Direct cost of malaria}

In Khartoum State, patients seeking care for malaria illness from governmental, NGOs, and private sector facilities - unless covered by health insurance - pay directly out of pocket for medical consultation, laboratory investigations and purchase of medicines. This user charge system, augmented by the limited coverage by health insurance, was most probably behind the high average treatment expenditure per fully cured case when compared with values from other countries. For instance, in Sri Lanka, Attanayake and colleagues reported a value equivalent to US\$ 1.1 for malaria cases visiting public health facilities where services are provided free of charge [1].

Our study and many others have shown that the highest proportion of treatment expenditure for malaria goes on medi- cines $[11,12]$. Thus where chloroquine, the cheapest drug, is still effective, the average expenditure per case is expected to be relatively low. However, in Khartoum State, chloroquine was replaced with the more expensive artesunate plus sulfadoxine-pyrimethamine combination therapy during the year 2004, and the complete establishment of this replacement is expected to increase the treatment-related expenditure even further.

The difference in the pattern of careseeking behaviour was also behind the inconsistency in treatment costs. Unlike the trend in other malaria-endemic countries $[1,3,13]$, there was high use rate of health facilities and low rate of self-treatment during malaria episodes in Khartoum State. This practice is probably motivated by the high coverage of health facilities provided by both the public and private sectors [14]. As reported by studies from other endemic countries $[6,11,2,14]$, the treatment-related expenditure was found to be significantly 
higher for those using health facilities than for those who self-treat. It is worth mentioning that self-treatment is resorted to by malaria cases to cut down the treatment cost. However, the self-treatment can have serious repercussions. For example, it can result in under-dosing which will lead to drug resistance and increase the cost of treatment in the long run through the necessary introduction of expensive drugs.

Our findings agree with many other studies in that seeking care from private health facilities was associated with the highest expenditure per fully cured case $[1,15,16]$. The variations in treatment costs between the public and private sectors are due to the higher fees charged by the private sector for malaria management.

\section{Indirect cost of malaria}

The indirect cost of malaria depends on both the amount of time lost due to illness and the value of that time in financial terms. In Khartoum State Plasmodium falciparum is responsible for around $90 \%$ of all malaria cases [5]. This species is associated with a more severe disease that is followed by a prolonged period of weakness and disability $[16,17]$. In addition to that, Khartoum is considered an area of unstable transmission of malaria where the intensity of transmission varies across the years [8]. Conditions of unstable malaria transmission are associated with low immunity levels, longer periods of disability, and a high degree of clinical illness in adults [16-19].

Both these factors would imply a high average indirect cost in Khartoum State. However, we used an output-related method in this study to estimate the indirect cost so as to avoid over-emphasizing the burden. The output-related method takes into consideration only time lost by economically active individuals and specifically those who actually suffered income or output loss
[1], i.e. excluding economically inactive individuals and those who obtained paid sick leave. This leads to cost estimates that are less than the estimates generated by other methods that use some estimate of the average wage that includes all individuals above a certain age irrespective of whether they are economically active or not or if they actually lose any output or income due to malaria [1]. The output-related method was earlier used to estimate the indirect cost related to malaria in Sri Lanka [1].

The average indirect cost per fully cured malaria case of US\$ 3.2 (SD 9.2) found in our study lies towards the lower limit of the range of US\$ 0.68 to US\$ 25 reported by Chima et al. [2]. The choice of method to measure and value time loss is potentially an important explanatory factor of the variations in household costs reported to date [1].

The indirect costs estimated by our study were less than the direct costs and this concurs with most studies estimating malaria costs [2].

Occupation of the malaria case was found to considerably affect the indirect cost; those working within the formal sector (government and private employees and public sector workers) had significantly lower indirect costs compared with those working within the informal sector (casual labourers and the self-employed). The reason behind this was that the majority of employees and public sector workers were able to obtain paid sick leave for the period of their illness thus avoiding salary cuts. On the other hand, casual labourers, who work in construction and domestic service are paid on a daily basis and any loss of activity is associated with loss of earnings. Moreover these individuals do not usually enjoy the benefits of health insurance, which is restricted mostly to the formal sector; this exacerbates the economic burden that falls

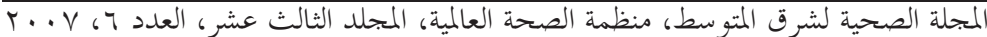


on them. However, although employees and public sector workers may not bear the direct effect of this indirect cost, the economy of a country suffers from the effect of these absences and, in the long run, this can have an impact on the individual.

\section{Conclusion}

Malaria places a great economic burden on households of Khartoum State in terms of direct and indirect costs. The indirect cost burden was especially tremendous on individuals belonging to the informal sector. High use rate of health facilities and the limited coverage by health insurance contributed to the high treatment cost. Reducing this burden requires strategies such as increasing coverage by health insurance to include all employees in the formal sector. For those belonging to the informal sector, provision of free malaria curative services should be considered. Regulation of prices of malaria services in the private sector should also be considered.

\section{Acknowledgements}

Funding for this study was provided by the Research Policy and Cooperation Unit of World Health Organization Regional Office for the Eastern Mediterranean.

We are very grateful to Dr Nimal Attanayake, Health Economics Study Programme, University of Colombo, Sri Lanka for providing the questionnaires that were of great help to us. We are also very grateful to the team of data collectors and field supervisors. Our thanks also extend to the households who participated in this study for their patience and cooperation.

\section{References}

1. Attanayake N, Fox-Rushby J, Mills A. Households costs of "malaria" morbidity: a study in Matale district, Sri Lanka. Tropical medicine and international health, 2000, 5(9):595-606.

2. Chima RI, Goodman CA, Mills A. The economic impact of malaria in Africa: a critical review of the evidence. Health policy, 2003, 63:17-36.

3. Asenso-Okyere KW, Dzator JA. Households cost of seeking malaria care. A retrospective study of two districts in Ghana. Social science \& medicine, 1995, 45(5):659-67.

4. Gallup JL, Sachs JD. The economic burden of malaria. Boston, Center for International Development at Harvard University, 1998 (www.eldis.org/static/DOC60.htm, accessed 12 July 2007).

5. Annual statistical report. Khartoum, Khartoum State Malaria Administration, 2001.
6. Worrall E, Basu S, Hanson K. The relationship between socio-economic status and malaria: a review of literature. Paper presented at the meeting "Ensuring that malaria control interventions reach the poor", London, 5-6 September 2002.

7. Rashed $\mathrm{S}$ et al. Economic impact of febrile morbidity and use of permethrinimpregnated bed nets in a malarious area. II. Determinants of febrile episodes and the cost of their treatment and malaria prevention. American journal of tropical medicine and hygiene, 2000, 62(2):181-6.

8. National strategic plan for RBM, 2001 to 2010. Plan of action. Khartoum, National Administration of Malaria, Federal Ministry of Health, Sudan, 2001.

9. Malik EM et al. Stratification of Khartoum urban area by the risk of malaria transmission. Eastern Mediterranean health journal, 2003, 9(4):559-68. 
10. Mustafa MS, Mustafa MH. The accuracy of the clinical diagnosis of malaria at the sentinel site of the disease surveillance system, Khartoum State. Khartoum, Research Department, Ministry of Health, Khartoum State, 2001.

11. Sauerborn $R$ et al. Seasonal variations of household costs of illness in Burkina Faso. Social science \& medicine, 1996, 43(3):281-90.

12. McCombie SC. Treatment seeking behaviour for malaria: A review of recent research. Social science \& medicine, 1996, 43(6):933-45.

13. Schellenberg JA et al. Inequalities among the very poor: health care for children in rural southern Tanzania. Lancet, 2003, 361:561-6.

14. Rashed $S$ et al. Economic impact of febrile morbidity and use of permethrinimpregnated bed-nets in a malarious area I. Study of demographics, morbidity, and household expenditures associated with febrile morbidity in the Republic of Benin. American journal of tropical medicine and hygiene, 2000, 62(2):173-80.
15. Ali HM. Community and hospital-based assessment of the cost of malaria case management in Wad Medani. Faculty of Health Sciences and Environmental Studies, 1998.

16. Booth CM, MacLean JD. Knowledge, treatment seeking, and socioeconomic impact of malaria on the Essequibo Coast of Guyana. McGill journal of medicine, 2001, 6:17-25.

17. MalaneyP.Microeconomic approachtoevaluating the burden of malaria. Boston, Center for International Development at Harvard University, 2003 (http://www.eldis.org/go/ display/?id=12642\&type=Document, accessed 15 July 2007).

18. Gomes M. Economic and demographic research on malaria: a review of the evidence. Social science \& medicine, 1993, 37(9):1093-108.

19. Goodman C et al. Economic analysis of malaria control in sub Saharan Africa. Geneva, Global Forum for Health Research, 2000. 